\title{
LAS DENOMINACIONES DE ORIGEN Y LAS RUTAS DEL VINO EN ESPAÑA: UN ESTUDIO DE CASO
}

\author{
Genoveva Millán Vázquez de la Torre
}

Universidad de Córdoba

\begin{abstract}
Resumen: Dentro de la actividad turística, la visita a bodegas cada vez está teniendo mayor importancia. Las rutas del vino como itinerarios culturales y avaladas por una Denominación Origen Protegida que certifique la calidad de sus caldos, pueden ser motores de desarrollo económico de las zonas donde se encuentran.

En este articulo se analiza el turismo del vino desde su concepto, la DOP que lo certifica y las rutas que se crean, estudiando en la última parte la DOP Montilla-Moriles, ubicada en el sur de España, que fue de las primeras en adherirse a la creación de una ruta pero de las menos conocidas por el turista enológico.
\end{abstract}

Palabras clave: Turismo enológico, Rutas gastronómicas, Montilla- Moriles, desarrollo económico.

Abstract: Protected designations of origin and wine route in Spain: a case study

Within the tourist, visiting wineries is having increasingly more important. The wine routes and cultural itineraries and backed by a Protected Origin Denomination certifying the quality of its wines, can be engines of economic development of areas where.

This paper examines the wine tourism from concept, that certifies the PDO and the routes are created, studied in the last part the Montilla-Moriles DOP, located in southern Spain, which was among the first to join to create a route of the least known but the wine tourist.

Key Words: Wine tourism, gastronomic routes, Montilla-Moriles, economic development.

Resumo: As denominacións de orixe e as rutas do viño en España: un estudio de caso

Dentro da actividade turística, cada vez está tendo maior importancia a visita a adegas. As rutas do viño como itinerarios culturais, avaladas por unha Denominación Orixe Protexida (DOP) que certifique a calidade dos seus caldos, poden ser motores de desenvolvemento económico das zonas onde se atopan.

1 Facultad de Ciencias Económicas y Empresariales. Universidad de Córdoba. C/ Escritor Castilla Aguayo ${ }^{\circ}$ 414004 Córdoba. Telf +34957222159 gmillan@etea.com 
Neste artigo analízase o turismo do viño desde o seu concepto, a DOP que o certifica e as rutas que se crean. Na última parte estúdase a DOP Montilla-Moriles, situada no sur de España, que foi das primeiras en adherirse á creación dunha ruta, pero das menos coñecidas polos turistas enolóxicos.

Palabras clave: Turismo enolóxico, rutas gastronómicas, Montilla-Moriles, desenvolvemento económico

\section{INTRODUCCIÓN}

Las visitas a bodegas son antiguas, remontándose a la época de la Antigua Grecia y Roma, pero no es hasta la época del Grand Tour cuando existen los primeros registros de viajes organizados para este fin. No obstante fue en el siglo XIX cuando el vino surgió como una forma de turismo de interés especial, que cubre las necesidades demandadas por un segmento en creciente auge, el enológico.

El turismo enológico es aquel que tiene su origen en las diversas manifestaciones del mundo del vino: las tradiciones, los negocios, la salud, la gastronomía, las competiciones, el folklore... etc, orientadas al turismo.

Según la Western Australian Wine Tourism Strategy (2000) (Charters y Ali-Knight, 2002), el turismo del vino es el viaje que se desarrolla con el propósito de tener experiencias con bodegas y regiones del vino, así como con sus estilos de vida. Es una experiencia que posee un elevado componente formativo o de conocimiento del vino, del lugar y sus tradiciones, y por tanto está estrechamente vinculado a la cultura, vino y gastronomía.

Esta definición tiene un componente vivencial acorde con las tendencias actuales, mientras que Hall et al. (2000) lo definen como la visita al viñedo, bodega, vinos y fiestas del vino y la uva, que se ponen a disposición para la degustación de vinos y/o contacto con los atributos de un vino de la región.

El negocio de enoturismo ha experimentado un desarrollo importante en todo el mundo. Australia, Nueva Zelanda, California, Sudáfrica y América del Sur son las nuevas fronteras del enoturismo.

Así, Elías (2006) define al Turismo del vino como los viajes y estancias dirigidas al conocimiento de los paisajes, las labores y los espacios de la elaboración del vino, y las actividades que acrecienta su conocimiento y adquisición y pueden generar desarrollo en las diversas zonas vitivinícolas.

El producto enoturismo consiste en la integración bajo el mismo concepto temático de los recursos y servicios turísticos de interés existente y potenciales de una zona vitivinícola (AVINTUR). Los ejes fundamentales para conceptualizar de forma adecuada el turismo del vino son que: (a) el turismo del vino es una estrategia de los destinos para desarrollar atractivos vinculados al sector del vino, participando empresas e instituciones, (b) El turismo del vino determina un arquetipo de comportamiento en el consumidor de vinos, los amantes e interesados del vino o los que poseen interés en visitar regiones vinícolas tienen respuestas diferentes ante vivencias similares y (c) que el turismo del vino es 
la oportunidad que poseen las bodegas para ser formadas en las capacidades comerciales que deben desarrollar ante consumidores, actuales o nuevos (Díaz, 2008).

El turismo del vino ofrece muchas oportunidades de desarrollo local a los territorios con producción vitivinícola, cultura y bienes ambientales y paisajísticos histórico-arquitectónicos representan una herramienta importante para atraer al turista.

A las características comerciales tradicionales del vino, se le ha incorporado otro valor agregado con rasgos más cualitativos, el atractivo turístico. Este fenómeno que se extiende a escala mundial, es una nueva forma de hacer turismo, al promover el conocimiento de la actividad vitivinícola en su totalidad y en el lugar de origen. Esta alternativa se la conoce con el nombre de enoturismo o turismo del vino.

Por enoturismo se entiende el desarrollo de las actividades turísticas y de ocio y tiempo libre dedicadas al descubrimiento y disfrute cultural y enológico de la viña, el vino y su territorio (Carta Europea del enoturismo). Los pilares del enoturismo europeo (Vademécum del Enoturismo Europeo) se definen:

Cultura del vino: Es importante destacar el valor enológico-cultural de los recursos o servicios enoturísticos. Sin cultura del vino, no hay enoturismo. La cultura del vino es el eje temático de este producto/servicio y el turista debe percibirlo durante todas las etapas de su viaje enoturístico y en cualquier componente de la cadena de valor enoturística. El carácter distintivo de los diferentes territorios se manifestará a través del vino y todas sus manifestaciones culturales: en las características arquitectónicas de la zona y bodegas, en festivales, en folclore, en la forma de trabajar la tierra y cultivar la vid, etc.

Turismo: El turismo y el turista son dos factores clave que determinarían claramente la demanda y la oferta del producto enoturístico. El turista como elemento clave del negocio turístico debe estar en el punto de mira de cualquier medida o desarrollo en el lado de la oferta enoturística. Un aspecto de especial importancia para el éxito del desarrollo enoturístico es la calidad de los equipamientos turísticos de que dispone el destino y un mínimo de servicios complementarios.

Territorio: El territorio desempeña un papel muy importante y se establece como base o marco de referencia del desarrollo de la oferta ecoturísticas en el destino. El territorio de la Ruta Europea del Vino estará compuesto por espacios naturales, espacios urbanos y por un entorno o ambiente general que lo identifique y que le confiera su carácter distintivo e identificativos. Para garantizar el carácter enológico de una ruta, este territorio debe estar vinculado a una D.O.P.

Sostenibilidad: Es importante destacar que el enoturismo europeo ha de desarrollarse bajo los principios del turismo sostenible. Según la Organización Mundial de Turismo (OMT), los principios que definen el turismo sostenible son:

- Los recursos naturales, culturales y otros se conservan para su uso continuado en el futuro al tiempo que reportan beneficios a la sociedad cultural.

- El desarrollo turístico planifica y gestiona de forma que no cause serios problemas ambientales o socioculturales

- La calidad ambiental se mantiene y mejora 
- Se mantiene un alto nivel de satisfacción de los visitantes y el destino retiene su potencial comercial y su prestigio.

- Los beneficios del turismo se reparten ampliamente por toda la sociedad.

Figura 1. Concepción del Turismo del vino

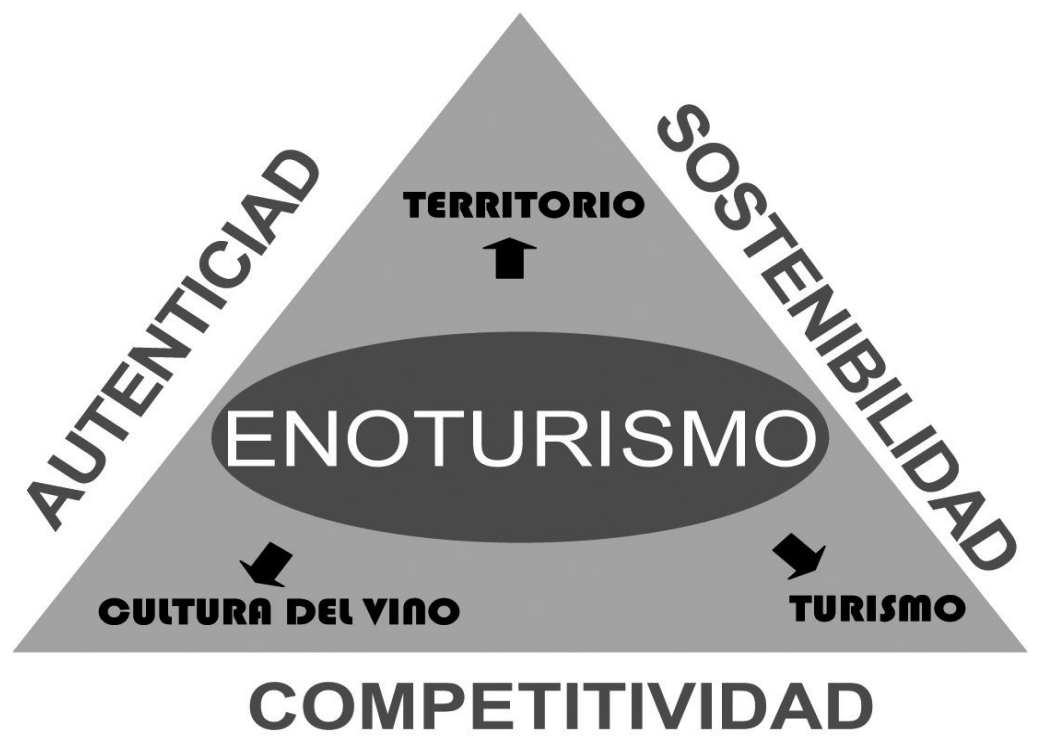

Fuente: RECEVIN

Autenticidad: La autenticidad del territorio y de la experiencia enoturística son factores muy valorados por el enoturista experimentado. Frente al turismo de masas producido en cadena y dirigido a un público escasamente diferenciado y con bajos niveles de exigencia.

Competividad: La Competitividad de un destino enoturístico es el resultado de adaptar su oferta de productos y servicios y sus sistemas productivos a los cambios del mercado, y de hacerlo de manera que sea sostenible en el uso de los recursos, socialmente beneficiosos y rentables a largo plazo. En este sentido, existe una relación directa y clara entre el concepto de sostenibilidad y la competitividad. La sostenibilidad de un destino enoturístico no se puede entender sin la competitividad y viceversa.

Pero el enoturismo ha tenido y tiene retractores que han considerado al turismo más como una intromisión en sus actividades que como un negocio próspero y rentable. Precisamente los procesos de innovación de los aspectos vitivinícolas están impulsados por los propios empresarios, mientras que la innovación turística aún encuentra enormes reticencias, y son mayormente por iniciativa pública. Todo ello unido a las ataduras culturales y las tradiciones endogámicas de las sociedades rurales, unido a esa falta de concienciación y confianza han supuesto un freno en algunos casos para el desarrollo de esta tipología turística. Así pues, no será posible un pleno desarrollo de este sector turístico si no existe previamente una mentalización de todos los agentes sociales. 


\section{TIPOLOGÍA DE ENOTURISTAS}

Existen diferentes estudios que analizan la segmentación psicológica del enoturista, tienen en cuenta los valores, actitudes y estilos de vida de los turistas del vino. Entre dichos estudios destacamos el realizado por Charters y Ali-Knight (2002) donde agrupa a los turistas en cuatro tipos diferentes:

1) Amantes del vino. Son aquellas personas que tienen una vasta educación en temas enológicos, siendo la motivación principal de su viaje catar diferentes tipos de vino, comprar botellas y aprender in situ. A su vez, también están muy interesados en la gastronomía local.

2) Entendidos del vino. Son aquellas personas que aunque no tienen una vasta educación en temas enológicos, conocen relativamente bien el mundo del vino. Suelen tener una formación universitaria y la motivación principal de su viaje es llevar a la práctica lo que han leído en diferentes revistas especializadas.

Figura 2. Perfil del enoturista según Charters y Ali-Knight (2002).

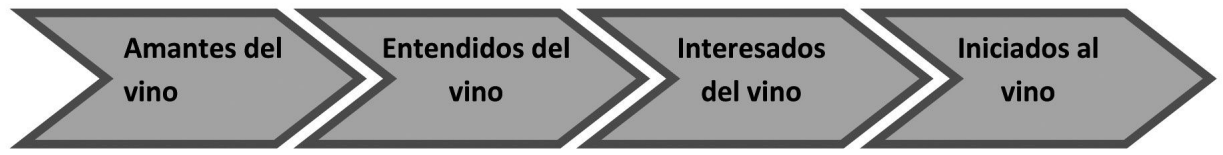

Fuente: Elaboración propia

3) Interesados del vino. Son aquellas personas que no tienen una formación técnica en temas enológicos pero le interesa este mundo. La motivación principal de su viaje es conocer algunas bodegas, aunque no con carácter exclusivo sino como complemento a otras actividades.

4) Iniciados al vino. Son aquellas personas que por diferentes razones (como la publicidad de una ruta o el querer tener nuevas experiencias) se acercan a una bodega sin tener ningún tipo de conocimientos en este campo. La motivación principal del viaje es otra totalmente diferente, pero aceptan, de forma secundaria, pasar unas horas visitando una bodega. Las compras que suelen realizar en la misma se destinan a consumo particular o, en la mayoría de las ocasiones, a regalo.

El enoturista puede mostrar diferentes características dependiendo de la zona que visite, ya sea Europa o las nuevas regiones productoras. Mitchell et al. (2000) citan el ejemplo de una investigación actual italiana, donde la segmentación se basa en el estilo de vida, dando cuatro tipos de enoturistas:

El profesional: 30-45 años, conoce los vinos y vinos del mundo, puede discutir sobre agudos puntos con el bodeguero y puede de manera competente juzgar las virtudes y faltas de un vino, siempre interesado en nuevas cosas y deseando dedicar tiempo y energía a sus descubrimientos. 
El apasionado neófito: 25-30 años, bien situado, le gusta el vino y lo ve como vehículo para cimentar la amistad, disfruta la comida, y explora el campo; generalmente viaja con amigos, algunos de los cuales pueden ser profesionales, y siempre tiene un guía del vino de bolsillo; motivado para aprender, pero menos serio sobre el vino que el profesional.

"El parásito": 40-50 años, rico, atraído por los vinos por tener algo de conocimiento sobre ellos y ello ser considerado una marca de distinción; está satisfecho con el conocimiento solo de lo básico, y es más fácilmente influido por los comentarios de otros que los de aquellos que pertenecen a las categorías mencionadas anteriormente; se decanta también por nombres famosos, y se impresiona más fácilmente por las apariencias, algunas veces pide descuentos.

El bebedor: 50-60 años, visita bodegas como parte de un grupo los domingos, tratándolas como una alternativa al bar, traga vino y pide más, también pide comprar en grandes envases y algunas veces se lleva un barril en la parte de atrás del coche.

Figura 3. Perfil del enoturista según Mitchell et al. (2000).

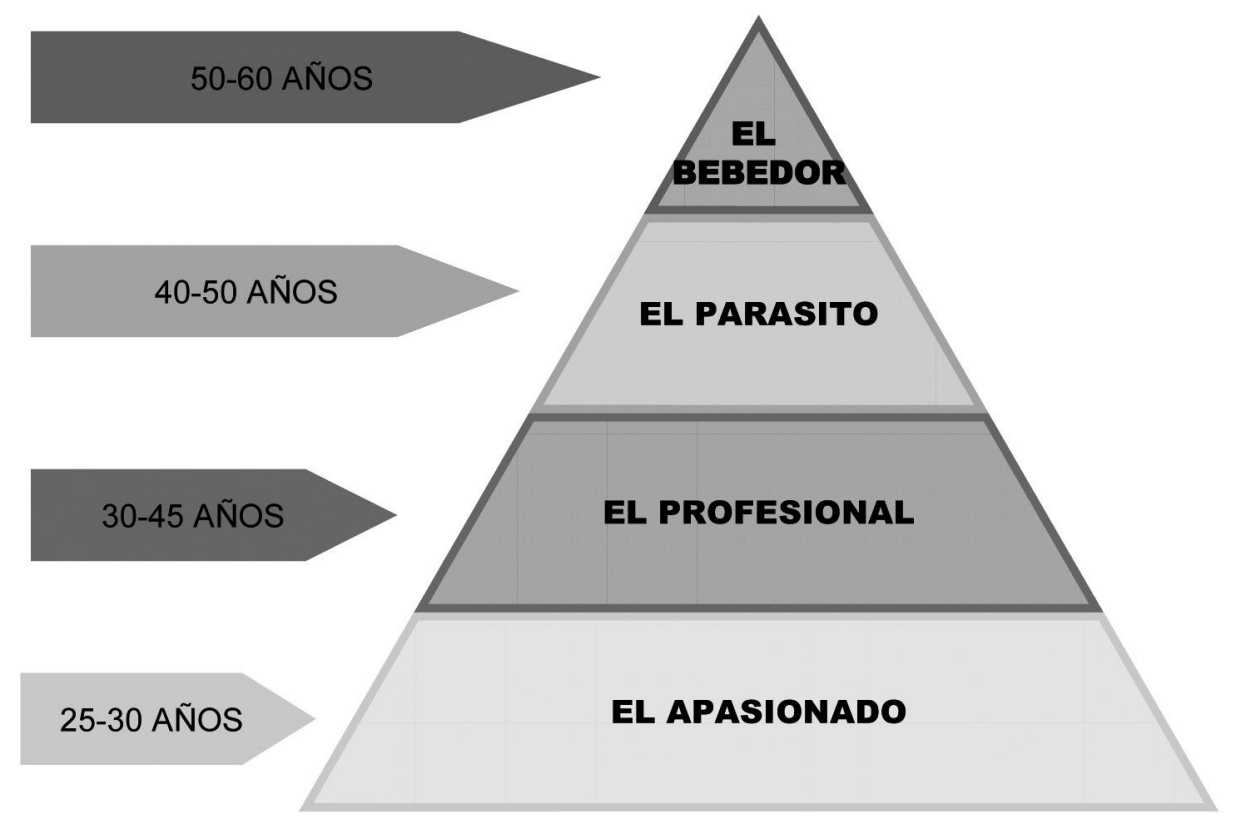

Fuente: Elaboración propia.

Es necesario analizar el perfil del consumidor turístico, para ofrecerle las actividades que demande, es por tanto imprescindible conocer sus gustos y preferencias para adaptar el producto/servicio turístico ofertado a la demanda exigida. 


\section{LAS DENOMINACIONES DE ORIGEN PROTEGIDAS DEL VINO EN ES- PAÑA}

Se entiende por Denominación de Origen Protegida (DOP) ${ }^{2}$ a la denominación geográfica de un país, de una región o de una localidad que sirva para designar un producto del mismo y cuya calidad o característica se deben exclusiva o esencialmente al medio geográfico, comprendidos los factores naturales y los factores humanos. Esta definición clásica proviene de la Reunión de Lisboa (1958), acuerdo internacional que pretendía el reconocimiento mutuo de las denominaciones de calidad (López, 2010).

El Ministerio de Medioambiente y Medio Rural y Marino define Denominación de Origen (DOP) como el nombre de una región, comarca, localidad o lugar determinado que haya sido reconocido administrativamente para designar el producto que cumplan las siguientes condiciones: (a) haber sido elaborados en la región, comarca, localidad o lugar determinados con uvas procedentes de los mismos; (b) disfrutar de un elevado prestigio en el tráfico comercial en atención a su origen; (c) y cuya calidad y características se deban fundamental o exclusivamente al medio geográfico que incluye los factores naturales y humanos; (d) además, han de haber transcurrido, al menos, cinco años desde su reconocimiento como producto de calidad con indicación geográfica (MAPA, 2009).

En Europa, pero sobre todo en España, la industria vinícola ha sido pionera en la utilización de nombres geográficos para identificar los productos alimenticios, mediante el distintivo de DOP. Cada DOP tiene unas normas especificas implantadas por el Consejo Regulador, relativas al área de producción, las variedades de producto, las prácticas de recolección, elaboración del producto, embotellado y controles de calidad, lo que favorece la percepción por parte de los consumidores de cierto grado de homogeneidad, al menos en los estándares mínimos de calidad, de las marcas amparadas bajo la misma DOP. Este certificado de calidad suscita una serie de connotaciones, tales como reconocimiento, calidad, reputación y lealtad, los cuales generan un valor intrínseco a la DOP, valorado tanto por los productores como por los consumidores. Desde la perspectiva del productor, dicho valor puede repercutir en los resultados económicos y financieros mientras que desde la perspectiva del consumidor, proporciona utilidad y puede constituir en si misma una variable decisiva en la elección, junto con otras variables, como el precio, variables de decisión comercial de productores y distribuidores (Resano et al., 2004).

Las DOP son las distinciones de calidad alimentaria más conocidas popularmente aunque el Ministerio de Medioambiente y Medio Rural y Marino en materia de alimentación otorga otras como son las Denominación de Origen Calificada (DOCA), que deberá cumplir, además de los requisitos exigibles a las denominaciones de origen, los siguientes:

\footnotetext{
2 Las DOP son instituciones jurídico-mercantiles dentro del derecho industrial, y que persiguen la defensa de los productores asociados a la misma y de los consumidores de dichos bienes al monopolizar el uso de determinados nombres comunes (De la calle, 2002). Las DOP pueden considerase un mecanismo capaz de superar problemas de información asimétrica en los mercados así como de definición de derecho de la propiedad.
} 
(a) Que hayan transcurrido, al menos, diez años desde su reconocimiento como DOP.

(b) Se comercialice todo el producto desde empresas inscritas y ubicadas en la zona geográfica delimitada.

(c) Cuente con un sistema de control desde la producción hasta la comercialización respecto a calidad y cantidad, que incluya un control físico-químico y organoléptico por lotes homogéneos de volumen limitado.

(d) Está prohibida la coexistencia en la misma bodega con vinos sin derecho a la DOCA, salvo vinos de pagos calificados ubicados en su territorio.

(e) Ha de disponer de una delimitación cartográfica, por municipios, de los terrenos aptos para producir vinos con derecho a la DOCA (MAPA; 2009).

Hasta marzo de 2012 estaban catalogadas en España 178 D.O.P de las cuales el $45,5 \%$ corresponden al vino, mientras que el 54,5\% restante engloba a productos variados (carnes, hortalizas, pescados, productos de panadería, quesos etc.), destacando las denominaciones de origen del queso que engloban el 23,65\% del valor económico de la comercialización por tipo de producto, mientras que el vino no supera el $2 \%$, no son por tanto importantes desde el punto de vista económico sobre el total, pero si desde el punto de vista turístico, pues son las más visitadas.

Tabla 1. Distribución de productos agroalimentarios, vinos con Denominaciones de Origen e Indicaciones Geográficas Protegidas en España (marzo 2012).

\begin{tabular}{|c|c|c|}
\hline & D.O.P. & I.G.P \\
\hline PRODUCTOS AGROALIMENTARIOS & España & España \\
\hline $\begin{array}{l}\text { TOTAL D.O.P. e I.G.P. de PRODUCTOS } \\
\text { AGROALIMENTARIOS }\end{array}$ & $\begin{array}{c}97 \\
(54,5 \%)\end{array}$ & $\begin{array}{c}73 \\
(62,4 \%)\end{array}$ \\
\hline \multicolumn{3}{|l|}{ VINOS } \\
\hline VINOS con Denominación de Origen (DO) & 68 & \\
\hline VINOS con Denominación de Origen Calificada (DO Ca) & 2 & \\
\hline Vinos de Calidad con Indicación Geográfica (VC) & 3 & \\
\hline Vinos de Pago (VP) & 8 & \\
\hline Vinos con Indicación Geográfica (IG) & & 44 \\
\hline TOTAL D.O.P. e I.G.P. de VINOS & $\begin{array}{c}81 \\
(45,5 \%)\end{array}$ & $\begin{array}{c}44 \\
(37,6 \%)\end{array}$ \\
\hline TOTAL D.O.P. e I.G.P. & $\begin{array}{c}178 \\
(100 \%)\end{array}$ & $\begin{array}{c}117 \\
(100 \%)\end{array}$ \\
\hline
\end{tabular}

Fuente: Elaboración propia a partir de información del Ministerio de Agricultura, Alimentación y Medio Ambiente

Si se clasifican las DOP según los criterios: superficie cultivable de vid, producción de vino, número de bodegas y viticultores, los resultados son bastantes dispares.

De las 81 DOP, la más importante por superficie dedicada al cultivo del vino es la Mancha con 168 mil hectáreas (ha) (27,91\%), con más extensión que las 66 DOP con 
menor superficie, seguida de la Rioja con 63.942 hectáreas $(10,62 \%)$ y Cataluña con 48.337 ha $(8,03 \%)$.

Figura 4. Superficie cultivable de vid por DOP campaña 2010 (ha)

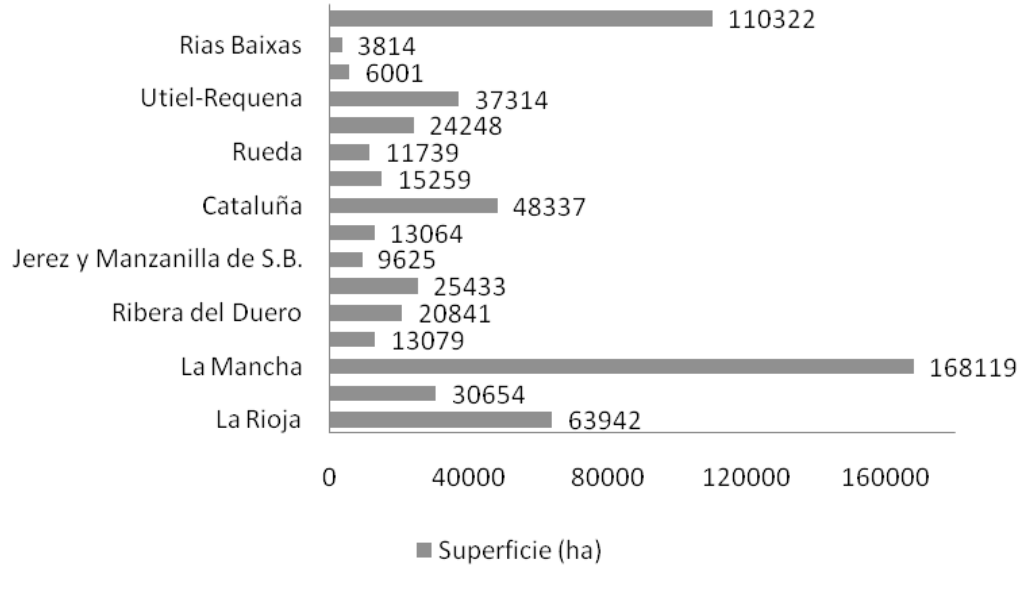

Fuente: Elaboración propia a partir de información del Ministerio de Agricultura, Alimentación y Medio Ambiente

Por producción de vino la D.O.P de mayor volumen es la Rioja, de los 12 millones y medio de hectolitros ( $\mathrm{hl}$ ), esta DOP produjo el 22,6\% del vino total, con más de 2,7 millones de hectolitros, seguida de la DOP de Cava (1,6 millones hl, 13,76\%) y la Mancha 1,3 millones hl, 10,9\%).

Figura 5. Producción de vino por DOP campaña 2010 (hl)

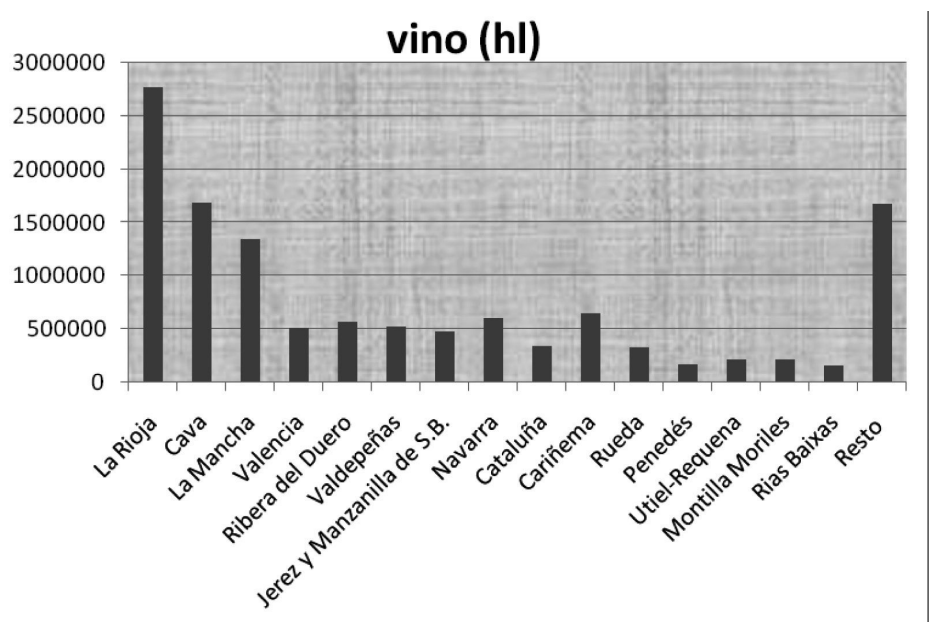

Fuente: Elaboración propia a partir de información del Ministerio de Agricultura, Alimentación y Medio Ambiente 
El número de bodegas inscritas sigue el mismo patrón de comportamiento que el de producción, así la Rioja tiene 1209 bodegas (26,53\%) seguida de Cava con 422 (9,26\%) y la Mancha $276(6,05 \%)$

Figura 6. Bodegas inscritas en la DOP campaña 2010

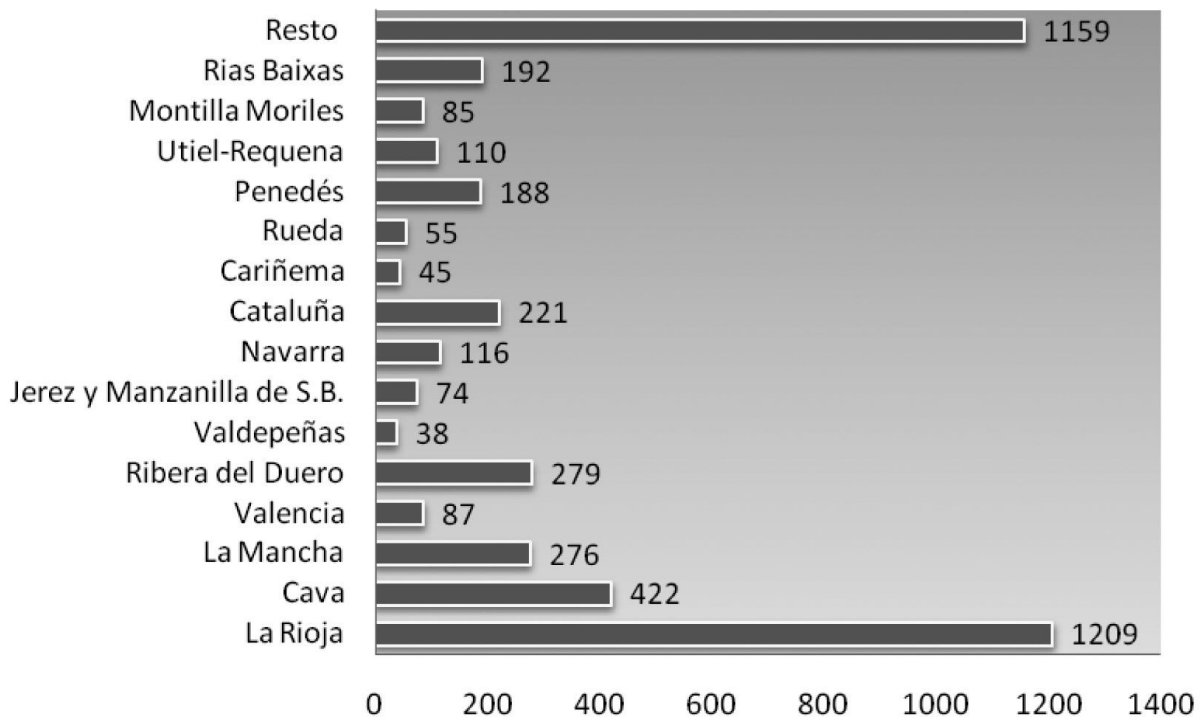

Fuente: Elaboración propia a partir de información del Ministerio de Agricultura, Alimentación y Medio Ambiente

Respecto al número de viticultores inscritos en la DOP, la Mancha y Rioja tiene un porcentaje similar (12,29 y 12,26\% respectivamente), seguida de Cataluña con un $10,17 \%$.

Analizando el ratio de superfice/viticultor, la extensión media de cultivo es de 4,19 ha, siendo desigual su distribución ( 9,53 ha en la Mancha a 3,63 ha en la Rioja).

Desde el punto de vista de la productividad (superficie/ producción), la producción media por ha es de $20,4 \mathrm{hl}$, siendo la de mayor rentabilidad la de Cataluña con 55,0 hl por ha seguida de la Rioja con 43,33 hl por ha, las de menos rentabilidad serian Utiel Requena (5,7 hl por ha), Cataluña $(7,16 \mathrm{hl}$ por ha) y La Mancha $(8,0 \mathrm{hl}$ por ha). 
Figura 7. Viticultores inscritos la DOP campaña 2010

\section{no viticultores}
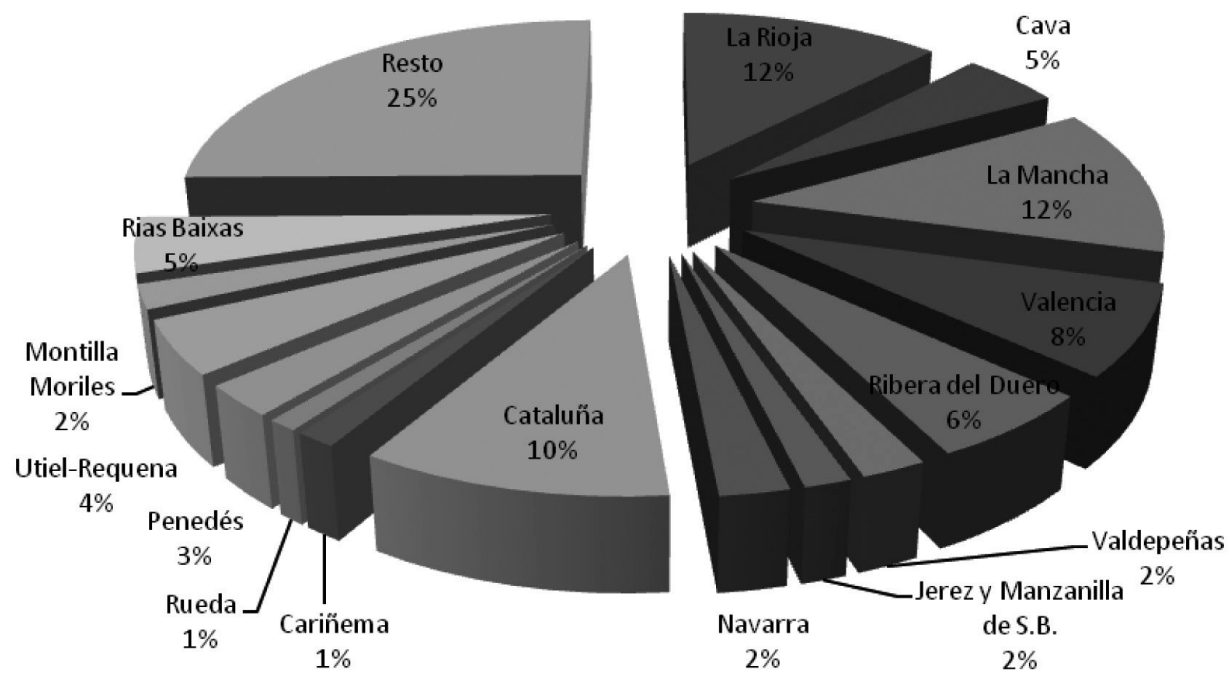

Fuente: Elaboración propia a partir de información del Ministerio de Agricultura, Alimentación y Medio Ambiente

La disparidad de producción y rentabilidad en parte, es debido a la no actualización por parte de las bodegas de sistemas de producción más avanzados, estando las bodegas más antiguas ubicadas en la región Manchega, siendo estos sistemas tradicionales un aliciente para reconvertir la bodega hacia el enoturismo, obteniendo los cooperativistas y empresarios un incremento adicional de rentas que complementan los ingresos de su actividad principal que es la de producción de vino.

\section{RUTAS DEL VINO}

Los cambios acaecidos en los hábitos de consumo han propiciado un interés creciente en productos de mayor calidad, diferenciados y adaptados a las nuevas necesidades de los diferentes grupos y segmentos del mercado. Dado este incremento en el consumo de productos diferenciados a partir de su calidad, una de las formas más apreciadas en el ámbito agroalimentario para lograr esta diferenciación son los certificados de calidad agroalimentaria, los cuales integran en su definición no sólo el origen geográfico sino, de una forma relevante, la tradición y especialización a la hora de elaborar productos de alta calidad y con personalidad diferente, como la reglamentación y los mecanismos de control sobre su producción (Márquez y Hernández, 2001). Las empresas agroalimen- 
tarias para incrementar su competitividad y conseguir su cuota de mercado tratan de establecer estrategias de diferenciación de sus productos, las cuales se basan en mostrar diferencias de atributos, materiales o características respecto al mismo producto de la competencia.

Así, el interés por los productos alimentarios y el turismo se ha materializado, por un lado, con el crecimiento de una restauración ligada a la cocina popular y a los productos de calidad autóctonos $\mathrm{y}$, por otro, en la consolidación de una nueva submodalidad de turismo: el turismo gastronómico (Armesto, X. A. y Gómez, B; 2004).

La creación de las rutas gastronómicas apunta resolver las dificultades de comercialización de los productos alimenticios regionales, pues se trata de un instrumento de promoción de los alimentos regionales. De esta manera, el uso de los indicadores geográficos de calidad facilita al consumidor el reconocimiento de la superioridad y de las cualidades diferenciadoras de cada producto. La potenciación del atributo origen o procedencia del producto se ha convertido así en un importante instrumento de marketing para la comercialización de productos y marcas, sobre todo si estas marcas pertenecen al sector agroalimentario (Martínez y Jiménez, 2006). El lugar de origen o procedencia de los productos puede convertirse en una importante fuente de ventaja competitiva para las empresas, capaz de influir en los consumidores a la hora de valorar productos o marcas (Agrawal y Kamakura, 1999).

Las rutas del vino, consideradas rutas gastronómicas por producto, son los recorridos señalados y publicitados con paneles especiales en los cuales se insiste en los valores naturales, culturales, medioambientales, viñedos y bodegas, explotaciones agrícolas individuales o cooperativas abiertas al público; estos constituyen el instrumento con el cual los territorios vitícolas y sus producciones relacionadas pueden ser divulgados, comercializados y disfrutados en forma de oferta turísticas ${ }^{3}$.

El concepto de ruta del vino consiste en constituir en determinados destinos rurales con orientación clara hacia el turismo cultural y rural un producto integrado basado en las actividades vitícolas, gastronómicas y culturales, acompañado por una amplia oferta de alojamiento con servicios relacionados con dicha actividad (enotecas, vinoteras, museos del vino, mueblerías especializadas) así como una amplia oferta de actividades complementarias como golf, hípica, oferta comercial, restaurantes, oferta nocturna.

Una ruta del vino no es solamente la señalización, sino son horarios seguros para los visitas a las fincas de viñedos, es la capacidad de guiar y mostrar su propia empresa, saber acoger y dar la bienvenida a un turista, es también la modificación estructural de la bodega, cuidar la limpieza y la oferta de la venta.

Una ruta del vino según Bruwer (2003) se caracteriza por la mezcla de agentes naturales, culturales y sociales, y además de actividades en bodega, la gastronomía local, actividades de observación del mundo del vino (como pueden ser los museos) y compra de productos locales artesanales y diferenciados. En una ruta o visita por todos

3 Les routes du vin Dans le monde a 30/06/2002, en www.arev.org 
los lugares y recursos relacionados con el vino o su estilo de vida (Raencroft y Van Westering, 2001), sin desvirtuar o hacer un uso excesivo de este estilo de vida del vino, dando lugar a ficciones o simulación.

La Secretaría de Estado de Turismo define la ruta del vino como "la integración bajo un mismo concepto temático de los recursos y los servicios turísticos de interés, existentes y potenciales, de una zona vitivinícola, planteados desde la autenticidad y la vocación vivencial, con el fin de construir un producto desde la identidad propia del destino, que facilita la comercialización conjunta de toda la zona y garantiza el nivel de satisfacción de la demanda, impulsando así el desarrollo económico-social integral de la misma".

A través del Programa "Calidad en los productos turísticos", la Secretaria General de Turismo, esta prestando asistencia técnica a destinos pilotos para diagnosticar la situación y evaluar los recursos, crear el producto turístico Rutas del Vino de España e implantarlo. El proyecto se inicio con las Rutas el Vino de El Penedés, Jumilla, La Mancha, Montilla-Moriles, Rías Baixas y Utiel-Requena.

Actualmente el proyecto reúne un total de 21 Rutas, 13 de ellas plenamente certificadas -Ruta del Vino de Bullas (Murcia), Jumilla (Murcia), La Mancha, Ruta del Vino y del Brandy del Marco de Jerez, Ruta del Vino de Montilla-Moriles, Navarra, Rías Baixas, Rioja Alavesa, Somontano (Aragón), Tacoronte-Acentejo (Canarias) y Ruta del Vino y del Cava del Penedès (Cataluña)- y otras 8 en proceso de certificación -Ruta del Vino de Ribera de Duero, Rioja, Condado de Huelva, Ribeiro (Galicia), Utiel-Requena (Comunidad Valenciana), Ycoden-Daute-Isora (Canarias), Alicante y Ribera del Guadiana (Extremadura).

ACEVIN (Asociación Española de Ciudades del Vino) y la Secretaría General de Turismo recogen en el Manual del Producto Turístico Rutas del Vino de España: la metodología para la implantación de este producto turístico y su posterior certificación por parte del Comité de Gestión y Certificación de las Rutas del Vino de España.

El producto Rutas del Vino de España trae asociados beneficios potenciales de diversa naturaleza que constituyen el valor añadido que este producto tiene con respecto a otras ofertas de turismo enológico y gastronómico ACEVIN)

- Para el cliente o visitante. El cliente obtiene sinergias en cuanto a poder conocer el entorno de elaboración del producto, y recibe en definitiva un servicio más amplio y profesional, respaldado por una institución con más fuerza y prestigio que cada una de las empresas individuales que la conforman.

- Para los empresarios. Supone la creación de una marca conjunta fuerte y distintiva en el mercado, asistencia mutua y colaboración, explotación de un nicho de mercado creciente y dinámico, desestacionalización de la demanda, introducción de sistemas de calidad de servicio, formación, central de compras y de ventas, promoción y comercialización conjunta.

- La autorregulación del sistema, de manera que son los Ayuntamientos, Consejos Reguladores y empresarios implicada en la Ruta del Vino los que adquieren el principal protagonismo en la conformación y puesta en marcha del producto. 
El turismo del vino impulsa el desarrollo socioeconómico integral y sostenible del territorio generando empleo, riqueza y, mejorando la calidad de vida de la población local. Fomentar la actividad turística en la DOP, posibilita la generación de nuevas vías de ingresos complementarios para los productores vitivinícolas, aumentar las ventas de vino.

Actualmente, según los estudios del observatorio de las rutas del vino de España, la ruta que más visitantes ha tenido ha sido la Ruta del Vino y el Cava del Penedès (Enoturisme Penedès que engloba a dos DOP la de Cava y Penedes) con 457.896 visitantes. La segunda ruta con mayor afluencia de visitantes fue la Ruta del Vino y el Brandy del Marco de Jerez (431.161 visitantes). Debemos comentar a este respecto que ambas zonas ecoturísticas cuentan con algunas de las bodegas más visitadas del mundo como pueden ser Codorniu y Freixenet en Penedès o González Byass Tío Pepe en el Marco de Jerez, que por sí mismas ya superan los 100.000 visitantes anuales. 


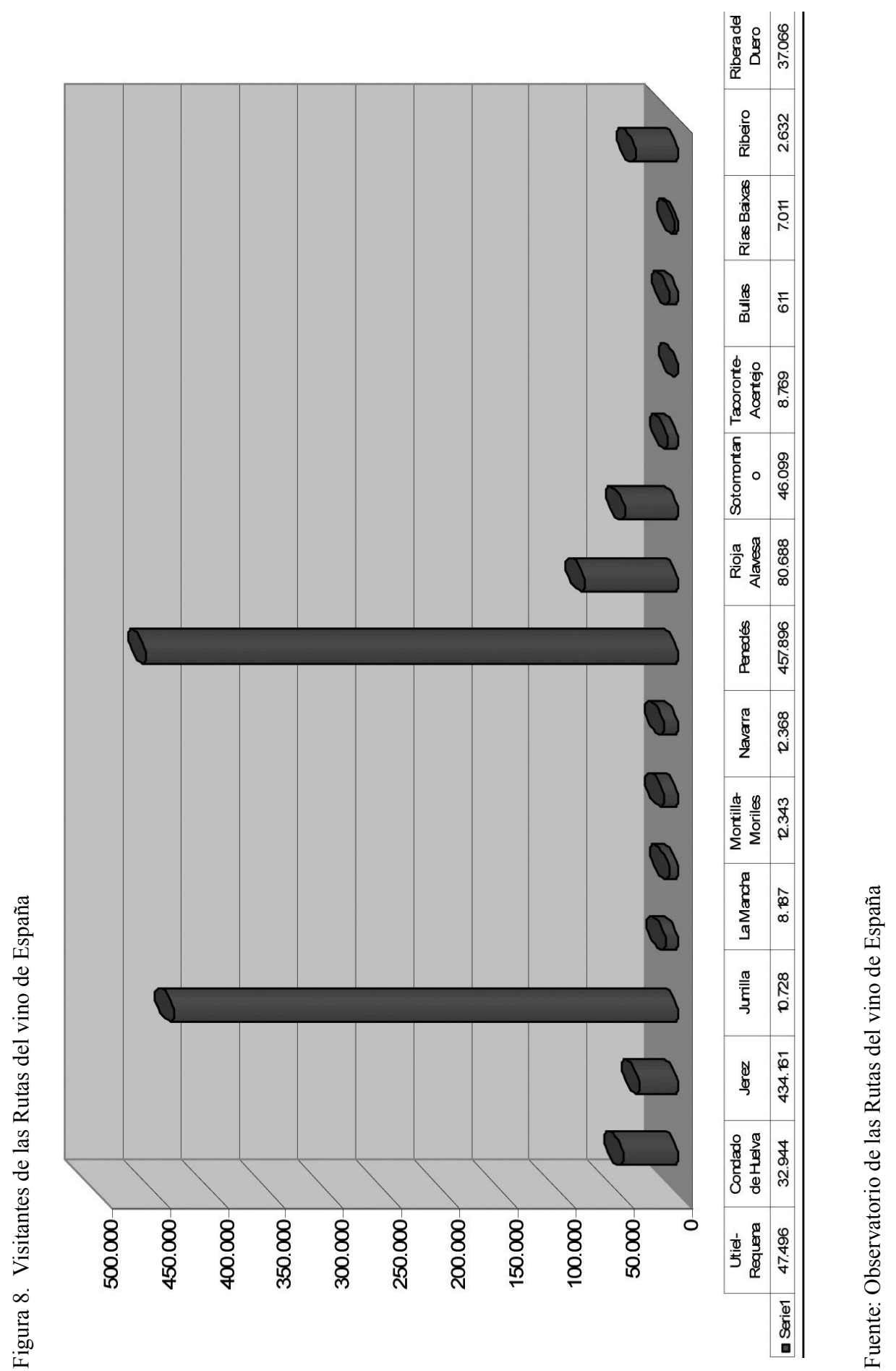


Como se observa por la figura 8 , suelen ser las DOP que tiene mayor producción de vino y mayor número de bodegas inscritas, las que han sido pioneras en crear rutas, asociándose varias denominaciones que por proximidad geográfica, beneficia al turista pues puede visitar varias bodegas, también suelen ser las que más producto del vino comercializan en el exterior, en parte porque el turista extranjero al visitarlas luego solicita los caldos para que estén en los lineales de los supermercados donde compran incrementándose la exportación.

\section{EL ENOTURISMO EN LA DENOMINACIÓN DE ORIGEN MONTILLA MORILES}

La Ruta del Vino Montilla-Moriles nace a principios de 2001, en el marco de los compromisos adquiridos por el Ayuntamiento de Montilla, como ciudad del vino, con la Asociación Española de Ciudades del Vino (ACEVIN). En abril de 2001 se constituye la Asociación para la Promoción del Turismo del Vino (AVINTUR), ente gestor que se ocupa de gestionar la Ruta del Vino Montilla-Moriles. En este momento (año 2012), forman parte de la ruta 52 entes públicos y privados, destacando especialmente bodegas $(34,6 \%)$ y restaurantes $(25 \%)$, siendo el municipio de Montilla el que concentra el mayor número de empresas inscritas $(53,84 \%)$. La ruta discurre por el sur de la provincia de Córdoba y atraviesa nueve municipios, presentando tres itinerarios diferentes, esta ruta está financiada, entre otros programas, por un plan de dinamización turística, aprobado en julio de 2005 y dotado con un presupuesto de 3,15 millones de euros

Tabla 2. Establecimientos adheridos a la Ruta Montilla-Moriles(2012)

\begin{tabular}{|l|c|c|c|c|c|c|c|c|c|}
\hline Tipo Establecimiento & Montilla & Moriles & Córdoba & Lucena & $\begin{array}{c}\text { Puente } \\
\text { Genil }\end{array}$ & $\begin{array}{c}\text { La } \\
\text { Rambla }\end{array}$ & $\begin{array}{c}\text { Aguilar } \\
\text { de la } \\
\text { Frontera }\end{array}$ & $\begin{array}{c}\text { Fernán } \\
\text { Nuñez }\end{array}$ & TOTAL \\
\hline Bodegas & 12 & 2 & & 2 & 1 & & 1 & 18 \\
\hline Restaurantes & 5 & & 4 & & 1 & 1 & 1 & 1 & $\mathbf{1 3}$ \\
\hline Hoteles, Hostales & 2 & & 1 & & & 1 & & & $\mathbf{4}$ \\
\hline Tabernas & & 1 & 3 & & & & & & $\mathbf{4}$ \\
\hline Enoteca & 1 & & & & & & & & $\mathbf{1}$ \\
\hline Alojamien Rural & 3 & 1 & & & & & & & $\mathbf{4}$ \\
\hline Tienda Especiali & & 1 & & & & & & & $\mathbf{1}$ \\
\hline Oferta Ocio & 3 & & & & & 1 & & & $\mathbf{4}$ \\
\hline Agencias Recept & 2 & & & 1 & & & & & $\mathbf{3}$ \\
\hline TOTAL & $\mathbf{2 8}$ & $\mathbf{5}$ & $\mathbf{8}$ & $\mathbf{3}$ & $\mathbf{2}$ & $\mathbf{3}$ & $\mathbf{2}$ & $\mathbf{1}$ & $\mathbf{5 2}$ \\
\hline
\end{tabular}

Fuente: Elaboración propia 
El marco de producción de la Denominación de Origen Protegida de Montilla Moriles se encuentra ubicado en la zona sur de la provincia de Córdoba. Los ríos Genil y Guadajoz limitan sus fronteras oriental y occidental, en tanto que el Guadalquivir, al Norte, y las Sierras de la Subbética, al sur, delimitan su contorno. Formado los términos municipales de Montilla, Moriles, Doña Mencía, Montalbán, Monturque, Nueva Carteya y Puente Genil en su totalidad, y en parte los de Aguilar de la Frontera, Baena, Cabra, Castro del Río, Espejo, Fernán-Núñez, La Rambla, Lucena, Montemayor y Santaella (Mapa 1).

El clima de Montilla-Moriles es básicamente mediterráneo pero con cierto carácter continental con influencia de los vientos que, proceden del Atlántico, entran por el Valle del Guadalquivir. Los inviernos son fríos y los veranos calurosos, largos y secos con una temperatura media máxima superior a $30^{\circ} \mathrm{C}$ y su pluviometría es escasa. Estas condiciones climáticas hacen que sea la primera vendimia de España, y que la obtención de los vinos sea totalmente natural.

Esta zona se encuentra relativamente bien comunicada, por carretera y ferrocarril, con las diferentes capitales de provincia de su entorno (fundamentalmente, Sevilla, Granada y Málaga). Asimismo, también está cerca de dos aeropuertos internacionales (Sevilla- Málaga), lo cual es un elemento decisivo para que ciudadanos de otros países consuman este producto turístico.

Dentro de la D.O.P se distinguen dos zonas: una Zona de Calidad Superior localizada en la Sierra de Montilla y los Moriles Altos, donde la tierra albariza provee las mejores condiciones para la obtención de vinos de calidad y otra denominada Zona de Producción.

Mapa 1. Localización de la Denominación de Origen Protegida Montilla Moriles
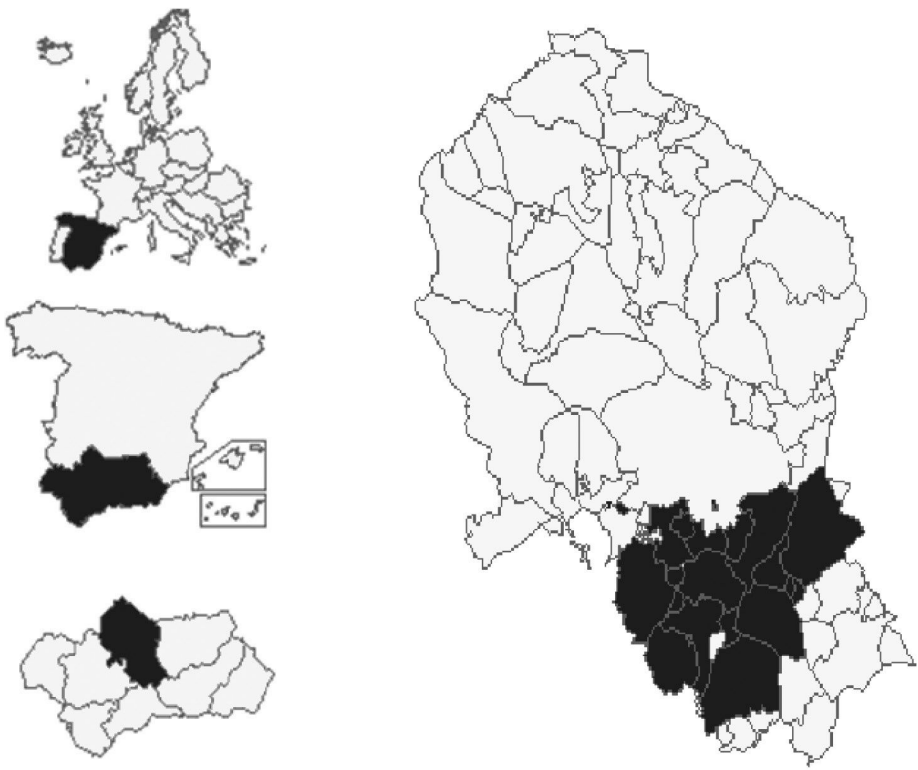

Fuente: Elaboración propia 
Aunque la DOP, está formada por 18 municipios sólo 9 forman parte de la Ruta Montilla-Moriles. El Patronato Provincial de Turismo de Córdoba, ha elaborado los tres itinerarios en los que está dividida la ruta que engloban la red vinarea ${ }^{4}$. El primero recorre Montilla-Moriles y se centra en las dos localidades que le da nombre a dicha denominación, y donde se encuentran las bodegas más importantes. La segunda recorre las ciudades de Córdoba, Fernán-Núñez, Montemayor, La Rambla y Montilla, y trata de unir el importante legado cultural y patrimonial de la ciudad de Córdoba con recursos turísticos de carácter rural. La tercera recorre las ciudades de Aguilar de la Frontera, Moriles, Lucena y Puente Genil.

En esta ruta el eje principal es visitar las bodegas y mostrar al turista el proceso de fabricación del vino, existe una preocupación por parte del empresariado (no cooperativo, como sociedades anónimas, limitadas o empresario individual) de adaptar las bodegas para que puedan ser visitadas y cumplan estándares de calidad, contando algunas de ellas con más de 100 años, siendo un legado patrimonial industrial importante y que produce un alto grado de satisfacción en el turista que las visita (Millan y Melian, 2010).

Mapa 2. Municipios que forman parte de la DOP Montilla-Moriles

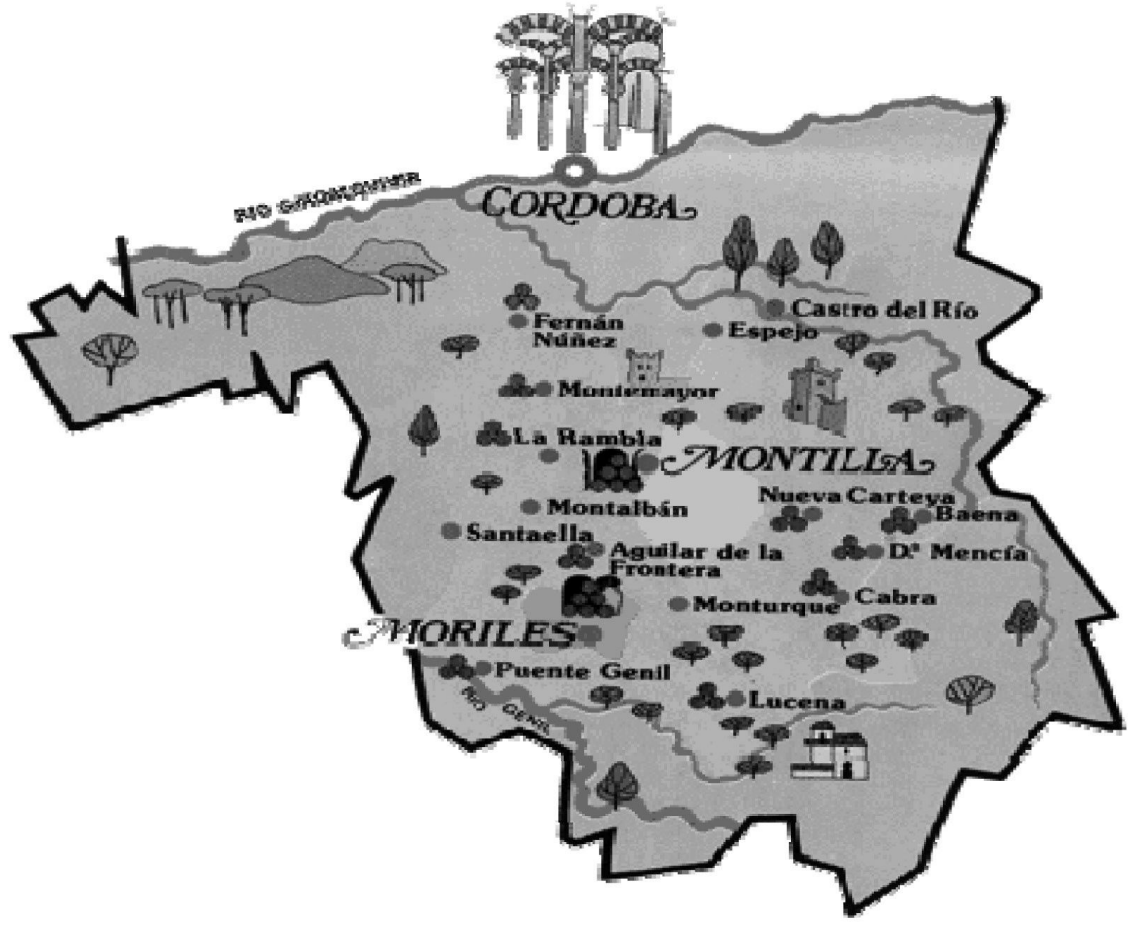

Fuente: DOP Montilla-Moriles

4 Formada por un conjunto de equipamientos turísticos de calidad, todos ellos relacionados con el turismo del vino y vinculados entre sí, (auditorio, centro de información permanente, Museo de la Campiña en Fernan Nuñez, Centro de interpretación de memoria histórica del vino etc... 
La DOP Montilla Moriles es una de las 15 más importantes de España, sin embargo su Ruta aunque fue de las primeras en estar certificada, no es tan conocida como la de La Rioja recibiendo poco más de 12 mil turistas al año. Aunque las autoridades locales (Ayuntamiento, Diputación, mancomunidad) están apostando fuerte por la promoción turística de esta zona basada en el producto vino de Montilla-Moriles.

Analizando socioeconómicamente los 9 municipios que forman parte de la ruta Montilla-Moriles (Tabla 3), entre los que se encuentra la capital de la provincia (Córdoba), cuenta en conjunto con una población de 464 mil habitantes, no obstante, se ha analizado la ruta sin tener en cuenta a la capital, ya que el turismo del vino es una actividad que puede ser residual dentro del computo de turistas de esta ciudad, ya que el principal objetivo de estos visitantes, es conocer la Catedral-Mezquita que es Patrimonio de la Humanidad, pudiendo distorsionar la visión económica del resto de los municipios de la ruta cuya principal actividad es la agrícola y no el sector servicios como ocurre en la capital de la provincia.

Con respecto a los datos de población de la ruta se comprueba que, según el Sistema de Información Multiterritorial de Andalucía (SIMA, 2012), el municipio de Lucena es el que tiene mayor número de habitantes censados (42.560) seguido de Puente Genil con 30.424 habitantes y Montilla con 23.870, estos tres municipios concentra la mayor parte de la población de la ruta $(71,2 \%)$. El resto de municipios de la zona se poseen una población entre 3.000 y 13.000 habitantes. Los habitantes mayores de 65 años suponen el $19 \%$ de la población de la ruta y el $24 \%$ de la población son menores de 20 años. 


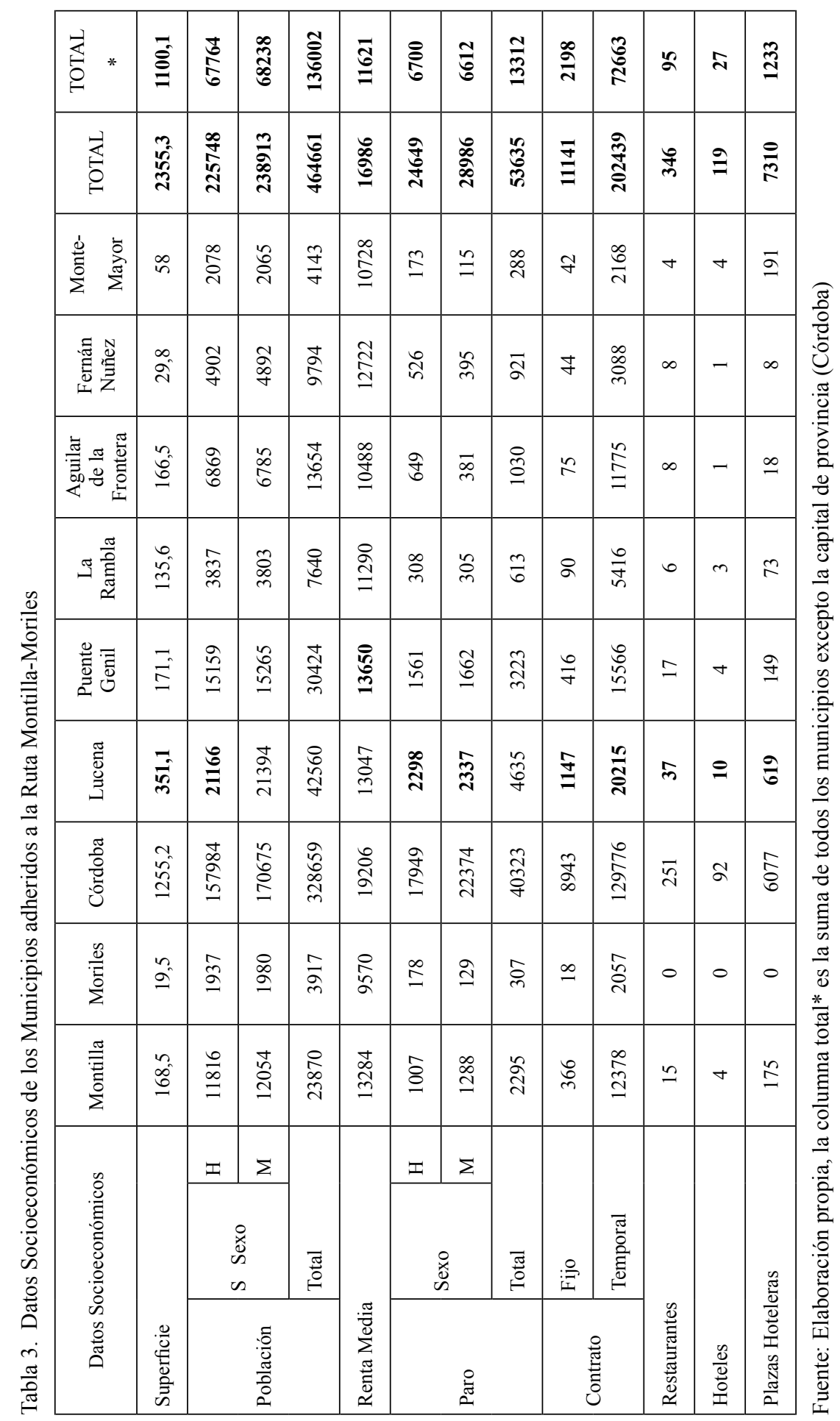


Respecto al mercado laboral, el número de trabajadores en paro es de 13.312 personas, siendo el porcentaje de varones ligeramente superior al de las mujeres $(50,3 \% \mathrm{y}$ $49,7 \%$ respectivamente) estando sus tasas de paro entorno (34,3\% y $36,2 \%)$, siendo esta una característica contraria a la evolución de la economía nacional donde el paro femenino es superior al masculino en más de un punto porcentuales $(25,41 \%$ y $24,68 \%)$, no obstante la provincia de Córdoba es una de las que tiene la tasa de paro más alta $37,75 \%$ (12 puntos porcentuales superior a la media nacional).

Otro rasgo a destacar de la Ruta, es el tipo de contrato, en el año 2011 se realizaron 74.861 contratos de trabajo de los cuales sólo el 2,93\% fueron fijos frente al 97,1\% eventuales, indicando la precariedad laboral de la zona, al igual que su bajo nivel de renta ya que esta es de 11.621 euros/año, pudiendo por tanto, el enoturismo ser una fuente de ingresos y crear riqueza en la zona, si previamente se fomenta, se estabiliza y se logra atraer más turistas que permitan a los empresarios obtener beneficio de las inversiones que tienen que realizar para adaptar sus empresas a las exigencias de la ruta, ya que según el estudio de Millán y Melián (2010) sólo el 61,6\% de los turistas visitan una sola bodega no necesitando pernoctar, en parte porque los horarios de visitas se limitan a las mañanas o visitas concertadas no estando la gran mayoria abiertas todos los días al público y especialmente los fines de semana que es cuando más turistas de los alrededores podrían hacerlo.

Figura 9. Número de bodegas visitadas en la Ruta del Vino Montilla-Moriles.
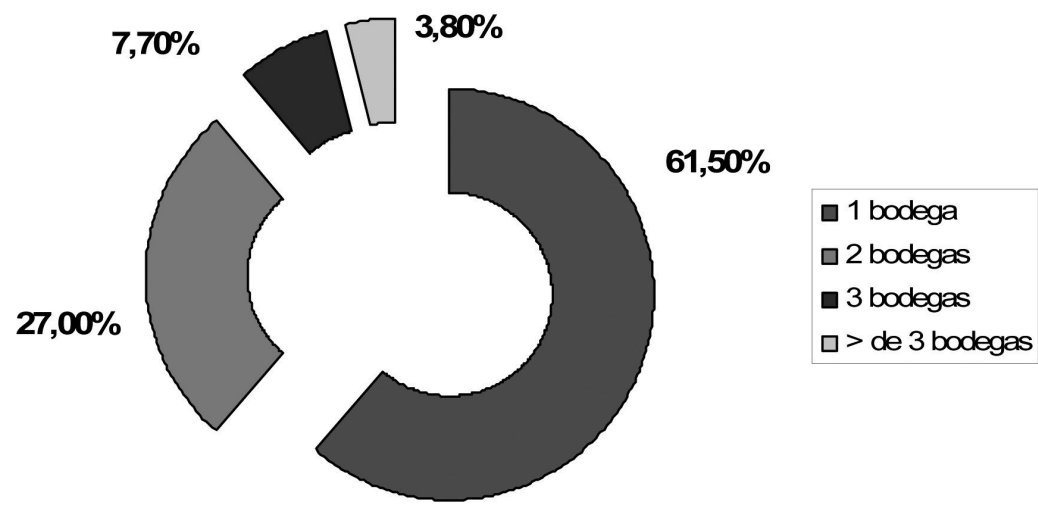

Fuente: Millán y Melián 2010

La demanda de enoturismo en la zona es creciente (Millán et al. 2008), por lo que existe una alta probabilidad de que el turista repita la experiencia, lográndose, por tanto, un alto grado de fidelidad. Esto nos lleva a plantear que existe una demanda mínima, para que diferentes empresas realicen inversiones en esta zona de cara a satisfacer este segmento turístico. El 84\% de las personas encuestadas recomendarían esta ruta turística, cifra que, en nuestra opinión, refleja el alto grado de satisfacción que este destino les proporciona a los turistas. 
No obstante, para mejorar la ruta se deberían incentivar la creación de más actividades complementarias, como podrían ser los festivales culturales o gastronómicos, ya que el principal destinatario del mismo es el turista de edad madura, lo cual generaría más ingresos para la zona, pero siempre acompañado de una mayor oferta de plazas hoteleras y casas rurales (figura 10).

Figura 10. ¿Qué mejoraría en la Ruta del Vino Montilla- Moriles?

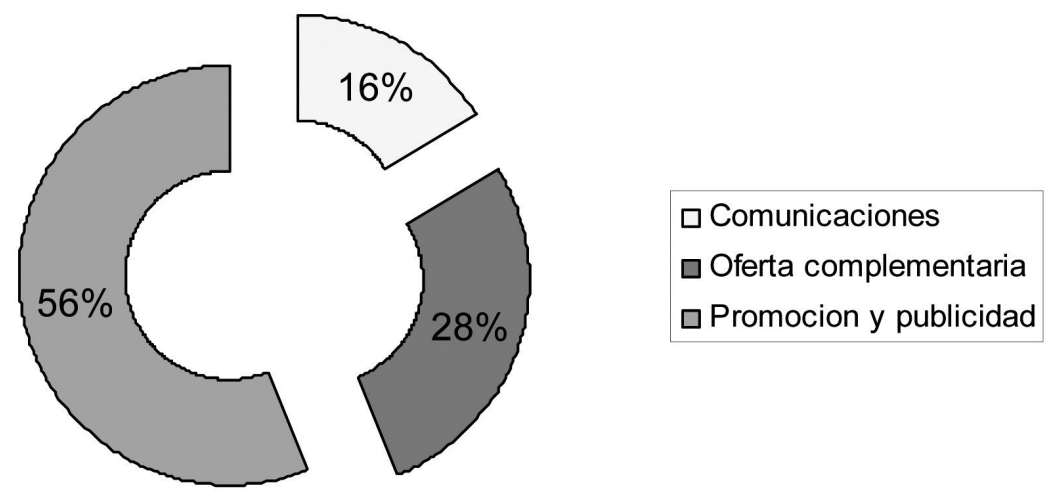

Fuente: Elaboración propia. López -Guzmán et al (2007)

Del estudio de Millán y Agudo (2011) se extrae que el perfil medio del enoturista que realiza la ruta del vino Montilla-Moriles es un trabajador cualificado de entre $50 \mathrm{y}$ 59 años, con un nivel de renta medio-alta, que viaja en familia y su principal motivación es conocer el vino, que considera que el trato recibido (hospitalidad) es bueno, pero que también opina que el precio del viaje es elevado y que la zona carece de actividades complementarias al de la propia visita a las bodegas.

El perfil predominante del turista del vino según los datos del Observatorio turístico de las Rutas del Vino de España, corresponde a un español, residente en el núcleo de población medio-grande que viaja en grupos pequeños, en periodos cortos y que se organiza personalmente su viaje aprovechando informaciones de amigos y familiares así como de Internet. Su nivel de gastos se sitúa por encima de la media nacional del gasto diario por turista y su índice de satisfacción. Resulta igualmente interesante como el $24 \%$ de los turistas realizan el viaje con amigos y compañeros de trabajo, lo que apunta como una actividad atractiva para viajes o eventos de empresa y el 57\% viaja con familiares. Como se aprecia ambos estudios describen un perfil de consumidor turístico similar.

\section{CONCLUSIONES}

La Ruta del vino de Montilla- Moriles, que se encuentra ubicada en la DOP de su mismo nombre, tiene todavía pocos turistas, aunque fue de las primeras rutas en certificarse, el desarrollo del turismo es incipiente y su crecimiento es lento aunque puede ser 
un motor de desarrollo de la zona si se logra compaginar con otras actividades que lo complementen y atraigan la atención del potencial turista.

El turismo del vino en la Ruta Montilla-Moriles puede impulsa el desarrollo socioeconómico integral y sostenible del territorio de la DOP, generando empleo estable en la comarca (disminuyendo la proporción de contratos eventuales y aumentando los fijos) si la actividad se promociona durante todo el año y no en la época de vendimia, incrementará la riqueza y mejorará la calidad de vida de la población local.

Existe una ausencia de una visión estratégica del sector que integre transversalmente agricultura, desarrollo y turismo, para que no se produzca una saturación del medio rural, para fomentar la sostenibilidad del medio ambiente, para generar riqueza y empleo.

El aumento de enoturistas puede traer consigo un crecimiento de las ventas de vino y del precio medio de venta de la botella, permitirá promocionar el producto a través de las catas en las bodegas y puede aumentar las exportaciones si la ruta se promociona en ferias internacionales, ya que incrementará el número de turistas extranjeros. Es necesario ofrecer la ruta a las agencias mayoristas de viajes, pues estas, son las que más turistas internacionales mueven y estos enoturistas poseen un nivel de renta superior al español y por tanto gastan más en productos vitivinícolas cuando los conocen.

El incremento de la actividad turística en la DOP Montilla-Moriles puede acabar con el turismo estacional, mejorar las infraestructuras y el entorno aumentando el incremento de la actividad turística en el territorio (turismo rural, gastronómico, etc.).

La zona de Montilla-Moriles( DOP y ruta) debería de adaptarse a este nuevo segmento turístico, el cual puede ser una vía de ingresos complementaria para los productores vitivinícolas a la vez que contribuye a mejorar la imagen del vino como producto y aumentar su efectividad comercial en los canales tradicionales.

Convendria impulsar una mayor coordinación entre las instituciones públicas y privadas con el fin de promocionar el turismo del vino. Para ello se ha de fomentar la coordinación entre los distintos municipios (de la DOP y la ruta) para cooperar en la difusión conjunta de las actividades de las distintas instituciones: publicaciones de un catálogo, de una página web, etc. Igualmente, se debe potenciar encuentros entre los entes públicos y privados con el fin de hacer una puesta en común de las acciones a llevar a cabo para desarrollar el turismo del vino Montilla-Moriles.

Se aboga por una especialización de la oferta en la Ruta Montilla-Moriles, para ajustarse a los cambios que tienen lugar en los hábitos del consumidor y satisfacer sus necesidades que, en definitiva, es lo más importante a la hora de fidelizar y de captar nuevos clientes, todo esto se conseguirá adoptando medidas para mejorar la imagen de la zona, fomentado el turismo participativo, en el que los visitantes puedan integrarse y sean partícipes de tareas y costumbres y modos de vida locales, y el rescatar actividades tradicionales, dará al producto y servicio ofrecido por la zona un grado de diferenciación con el resto de los destinos competidores.

Pero tanto las autoridades locales, empresarios y residentes se deberían de concienciar que han de, coordinar y planificar cualquier actividad e iniciativa turística que pueda generar un florecimiento y una prosperidad económica en la zona, que repercutirá en 
beneficio de todos los agentes, para ello es imprescindible condicionar el medio ambiente del lugar como atractivo turístico y promover el desarrollo estable y sostenido y aumentar el grado de compromiso de los habitantes de la zona en materia de turismo.

\section{BIBLIOGRAFÍA}

Agrawal, J. y Kamakura, W. (1999): "Country of origin: A competitive advantage?”, International Journal of Research in Marketing, 16(4): 255-267.

Armesto, X. A. y Gómez, B. (2004): "Productos agroalimentarios de calidad, turismo y desarrollo local: el caso del Priorat", Cuadernos Geográficos, 34: 83-94.

Bruwer, J. (2003). "South Africa Wine Routes: Some Perspectives on the Wine Tourism Industry's Structural Dimensions and Wine Tourism Product", Tourism Management, 24: 423-435.

Charters, S. y J. Ali-knight (2002): "Who is the wine tourist?", Tourism Management, 23: 311-319. Denominación de Origen Montilla- Moriles. www.montilla-moriles. org 29/12/08

Díaz, R. (2008):" Potenciación E integración del "turismo del vino" en un destino de sol y playa: El caso de Tenerife". PASOS. Revista de Turismo y Patrimonio Cultura, 6( 2 ): 199-212.

Diez, D (2011): “La planificación estratégica en espacios turísticos de interior: Claves para el diseño y formulación de estrategias competitivas", Investigaciones Turísticas, 1: 69-92.

Elias, L.V. (2006): El turismo del vino. Otra experiencia de Ocio. Documentos de Estudios de Ocio. Num. 30, Bilbao, Universidad de Deusto.

Diez, D (2011): "La planificación estratégica en espacios turísticos de interior: Claves para el diseño y formulación de estrategias competitivas", Investigaciones Turísticas, 1: 69-92.

Hall, M.; Sharples, L.; Cambourne, B. y N. Macionis (2000): Wine tourism around the wordl development, management and markets. Oxford. Elsevier Science.

López, J.A. (2010): Posibilidades de desarrollo del enoturismo en la denominación de origen Jerez-Xerry y manzanilla de Sanlucar de Barrameda y vinagre de Jerez. Boletín de la Asociación de Geógrafos Españoles, 53: 21-41.

Márquez, A. M. y Hernández, M. J. (2001): “Cooperación y sociedades cooperativas: el caso de la Denominación de Origen Sierra Mágina”. Revista de Estudios Cooperativos, Revesco, 74: 122-146.

Martinez, M. P. y Jimenez, A. I .( 2006): “La potenciación del origen en las estrategias de marketing de productos agroalimentarios: Objetivos, situación e implicaciones". Boletin Económico ICE, 2880:13-28.

Mitchell, R., Hall, C. M., y McIntosh, A. (2000): Wine tourism and consumer behaviour. In Hall, M., Sharples, L., Cambourne, B., y Macionis, N. (Eds.), Wine Tourism Around the World. pp. 115-135. Oxford: Butterworth-Heinemann 
Millán, G. y Melian, A. (2010): “Turismo enológico y desarrollo rural: una aplicación empírica". Lider(Osorno), 17: 159-175.

Millán, G.; Morales, E. y Agudo, E. (2010): "El oleoturismo como motor de desarrollo rural. La denomonación de origen Montoro-Adamuz". Mundo Agrario. Revista de Estudios Rurales, 11(21): 1-18.

Ministerio de Medio Ambiente y Medio Rural y Marino. http://www.marm.es/ .

Observatorio Turístico de las Rutas del Vino de España www.wineroutesofspain.com $25 / 08 / 09$

OMT. Organización Mundial de Turismo. Página web: www.word-tuorism.org

Resano, H.; A., Sanjuán I. y Albisu, L. M. (2004): Modelización de la elección entre vinos con D.O. Aplicación de un logit condicional a datos agregados. En: V Congreso Nacional de Economía Agraria. Santiago de Compostela del 15 al 17 de septiembre.

Sistema de Información Multiterritorial de Andalucía (SIMA). http://www.juntadeandalucia.es/institutodeestadisticaycartografia/sima/index.htm 